\title{
O teatro para crianças Perspectivas actuais
}

\author{
Glória Bastos
}

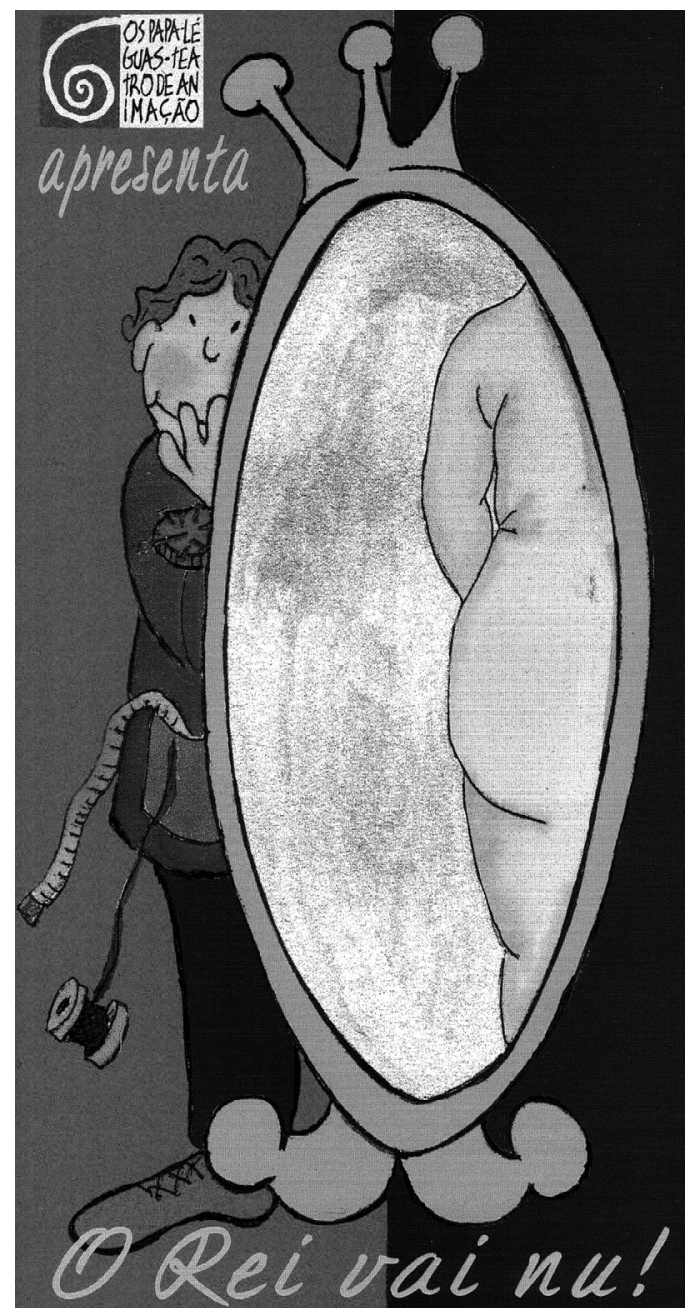

Introdução

Quando pretendemos abordar o panorama actual do teatro, tanto na vertente de textos dramáticos publicados como na da criação de espectáculos que têm como destinatário privilegiado as crianças, é quase inevitável uma menção inicial ao momento de viragem que foi a Revolução de Abril de 1974 e às circunstâncias políticas, sociais e culturais que permitiram, a partir de então, a existência de um movimento de expansão da actividade teatral para o público infantil. Esse movimento, embora seja caracterizado por diversas descontinuidades - no apoio à publicação de textos, na vida das companhias e dos festivais - vai reflectir, naturalmente, o momento de vitalidade cultural que sucede às transformações provocadas pela instauração do regime democrático, com o fim da censura (que também não se esquecia dos textos e dos espectáculos dirigidos aos mais novos), a melhoria das condições socioeconómicas e 0 alargamento da escolaridade, com reflexos evidentes nas relações com a cultura. Mas representa igualmente uma abertura da sociedade à idade infantil, um olhar mais atento aos seus interesses, às suas necessidades, aos seus direitos de acesso aos produtos culturais, em intima relação, não o poderemos esquecer, com a problemática educativa. Neste contexto, a escrita que tem como destinatário preferencial a criança conheceu um impulso de grande significado, concretizado na publicação de mais e melhores livros e no aparecimento de autores e ilustradores cujo trabalho de qualidade tem contribuido para o sucesso desta área no panorama editorial português.

0 consumo de teatro, durante a infância e a juventude, sofre uma forte influência do papel da escola enquanto instituição que, para lá da sua função mais estrita, deve possibilitar ainda o contacto com experiências e práticas culturais, onde a ida ao teatro assume, de facto, um lugar de destaque. E esta é uma dimensão a que se deve atribuir um merecido relevo, quer no campo da formação de públicos quer nas possibilidades oferecidas para a fruição estética. De qualquer forma, é nítido que nas quase quatro décadas que passaram sobre o 25 de Abril a realidade do teatro para crianças - tanto na vertente textual como espectacular - sofreu alterações profundas e mesmo se nem sempre o panorama para o qual olhamos nos satisfaz completamente, também não poderemos esconder que este território da produção cultural tem hoje uma visibilidade marcante.

Um exercício que facilmente comprova esta circunstância poderá ser o recurso a uma pesquisa simples na WWW. As expressões "teatro infantil" ou "teatro para crianças", no motor de pesquisa Google, revelam mais de dez mil entradas recentes em Portugal que remetem, sobretudo: (1) para notícias de variadíssimos eventos de teatro para os mais novos, nas mais diversas regiões (iniciativas de câmaras e de escolas, promoção de espectáculos, registos em órgãos de informação nacionais e regionais, etc.); (2) para páginas de divulgação de grupos e companhias que desenvolvem a sua acção nessa área (por vezes grupos que realizam actividades variadas de animação e expressão dramáticas - teatro de rua, contadores de histórias, formação, ateliês de expressão, etc.).

Estamos, portanto, situados num território multifacetado e que apresenta uma orgânica própria, que permite distinguir o teatro para crianças como uma forma de arte com especificidades bem marcadas, como acentuou
Programa do espectáculo O reivainu, texto e enc Mário Jorge, Teatro de Animação Os Papa-Léguas, 1999

\section{Glória Bastos}

é professora na Universidade Aberta e tem desenvolvido trabalho de investigação nas áreas da literatura para crianças e jovens e $d$ promoção da leitura. É autora do estudo $O$ teatro para crianças em Portugal: História e crítica (Lisboa, Caminho, 2006). 
David Wood: "o teatro para crianças é uma arte à parte, com qualidades que o tornam muito distinto do teatro para os adultos. Não é um teatro para adultos simplificado: tem a sua própria dinâmica e as suas próprias recompensas" (itálico no original) (Wood 1997: 5). É por isso que consideramos que este campo da cultura e da literatura portuguesas merece um olhar bastante mais atento do que aquele que tem sido adoptado no âmbito dos estudos sobre teatro. Procurando cumprir esse propósito, neste texto tentaremos sistematizar um conjunto de aspectos que caracterizam o panorama actual do teatro para crianças que nos é oferecido, tanto na esfera da escrita dramática como na sua dimensão performativa. 0 conteúdo deste texto será, portanto, mais de teor descritivo do que analítico, tendo-se optado igualmente por incluir a listagem de obras publicadas entre 1980 e 2012, inclusive, no sentido de proporcionar uma perspectiva mais exacta do que se tem passado neste terreno'.

\section{Teatro e texto dramático}

Iniciando este percurso pelo contexto que mais interesse nos tem suscitado, a da escrita dramática, um aspecto que desde logo se evidencia é o facto de a escrita para teatro, com a desejável publicação de textos originais, ocupar um lugar quase residual no seio da edição para os mais novos. Outro elemento que ressalta da análise realizada é que a maioria dos novos textos que vão conhecendo a letra de imprensa resultam de uma escrita teatral com fortes ligações ao espectáculo, na medida em que a perspectiva da sua colocação em cena está quase sempre presente, como são os casos de Manuel António Pina (cujos textos foram representados pelo grupo Pé de Vento) ou de António Torrado, cujas últimas peças têm sido postas em cena pela Comuna, ou ainda os textos para teatro de marionetas,

${ }^{1}$ Em relação ao elenco de peças de teatro para crianças (com base em textos publicados ou não) e de companhias que se movimentam nesta área, remetemos para consulta da base de dados CETbase, do Centro de Estudos de Teatro da Universidade de Lisboa, a que se acede através do

seguinte endereço: http://www.fl.ul.pt/CETb ase/default.htm.

${ }^{2}$ No campo da

literatura dramática para

adultos, publicam-se anualmente entre três cinco textos originais de autores portugueses (cf. Serôdio 1998). escritos por João Paulo Seara Cardoso e apresentados pelo Teatro de Marionetas do Porto.

Numa contabilidade que é sempre incompleta, na medida em que haverá certamente edições que não chegaram ao nosso conhecimento, podemos apontar que se publicaram entre quarenta e cinquenta livros por década ${ }^{2}$ desde 1980, contando com as reedições, que apesar de tudo são escassas (cf. listagem de peças no anexo). Na primeira década do século XXI nota-se também uma relativa concentração editorial, uma vez que a maior parte dos livros mencionados são da responsabilidade de duas casas editoras: Editorial Caminho e Campo das Letras. Refira-se ainda que a década de 80 beneficiou da existência de um prémio atribuido pela então Secretaria de Estado da Cultura, primeiro só a textos e depois também a produções teatrais situação que favoreceu a publicação dos textos premiados (na colecção Palco, da Moraes Editora). Actualmente não existe qualquer prémio exclusivamente para texto e/ou peça de teatro para crianças e nos últimos anos a edição tem sido escassa ou mesmo inexistente.

No que se refere às características que mais se destacam na escrita dramática actual para os mais novos, tivemos já a oportunidade de apresentar um estudo aprofundado sobre esse dominio (Bastos 2006) e onde se estabeleceram os traços essenciais, que aqui retomamos, com a necessária brevidade. Assim, nas peças publicadas nota-se uma presença forte da reescrita de textos tradicionais privilegiando-se o universo infantil e o discurso da fantasia e do humor. Em termos temáticos, há uma insistência na problemática da construção da identidade e uma incidência em personagens-crianças, quase sempre envolvidas em percursos de aprendizagem e de amadurecimento, ao lado de uma reflexão sobre certas preocupações sociais actuais (por exemplo, a defesa do ambiente). No aspecto formal as distinções maiores vão para a importância da relação comunicativa com o público (com frequência, directamente interpelado pelas personagens), que constitui um elemento fundamental na concepção de um "modelo" do teatro actual para crianças, e para o recurso frequente ao verso rimado, por vezes prevendo a existência de apontamentos musicais aquando da transposição do texto para espectáculo teatral, elemento que se tem acentuado nos espectáculos mais recentes, em que o teatro musicado assume alguma preponderância.

Mas o que a situação actual sobretudo demonstra é que a esta existência frugal do texto dramático publicado tem, por outro lado, correspondido uma bem mais robusta presença do espectáculo teatral para crianças. Na verdade nota-se algum vigor na multiplicação de propostas de espectáculos de teatro para a infância estabelecendo, todavia, uma relação particular com a vertente textual, pois na sua quase totalidade partem de textos não dramáticos que são adaptados para a linguagem teatral. Noutros casos ainda, estaremos perante criações específicas para um dado espectáculo, não chegando o texto a ser publicado.

A base de dados criada pelo Centro de Estudos de Teatro, da Faculdade de Letras de Lisboa (CETbase - Teatro em Portugal) permite-nos aceder a um importante conjunto de informações que clarifica bem a situação que descrevemos. No momento em que escrevemos este artigo, um percurso pelas companhias que nas últimas três décadas se têm dedicado ao teatro infantil revela sem dúvida esta faceta, pois são poucos os textos publicados que têm oportunidade de subir ao palco. Manuel António Pina emerge como o autor de textos para teatro infantil mais representado, seguido de António Torrado. No campo da adaptação teatral de contos infantis, surge destacado o nome de Sophia de Mello Breyner Andresen, sendo os contos A fada Oriana (4 registos), A menina do mar (14 registos) e 0 rapaz de bronze (7 registos) os textos desta autora que mais vezes têm sido retomados por companhias tão diversas como Teatro Bábá, Teatro do Noroeste ou TAS - Teatro Animação de Setúbal.

E podemos ainda associar outros nomes inevitáveis, como os irmãos Grimm, Charles Perrault ou Andersen, sabendo que uma das grandes fontes de inspiração para o teatro destinado aos mais novos continua a ser a literatura tradicional. A estes acrescente-se o nome de 


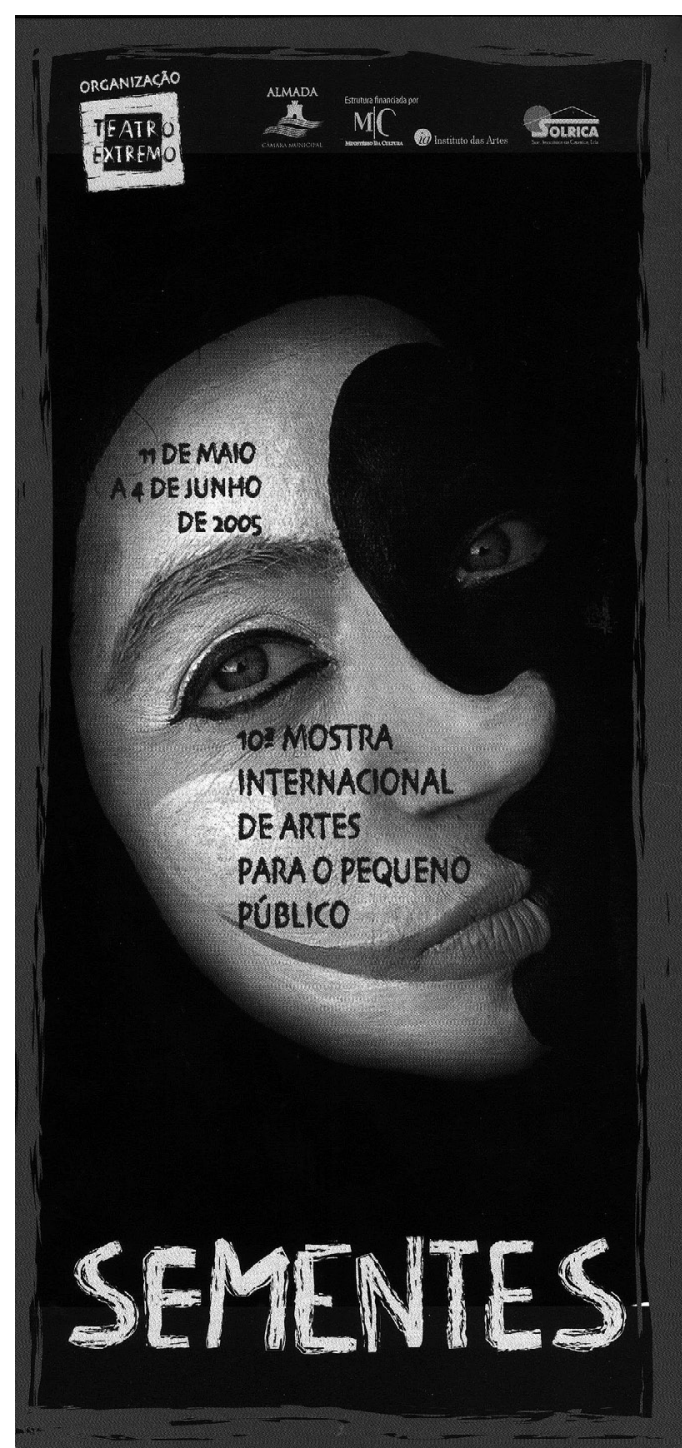

Lewis Carrol, pois a história de Alice é também uma das que mais vezes tem sido levada ao palco por grupos portugueses (14 apresentações diferentes registadas, 13 delas a partir de 1992). Ainda no campo da adaptação para teatro, note-se a presença de Aquilino Ribeiro, com a história de 0 romance da raposa a ser escolhida por sete companhias diferentes no período aqui considerado; de As aventuras de João sem Medo, de José Gomes Ferreira, também transpostas várias vezes para espectáculo teatral; de Luisa Ducla Soares, com vários textos seus, na esfera da narrativa e da poesia, a serem escolhidos como suporte para espectáculos de teatro (por exemplo, Os ovos misteriosos ou A gata tareca e outros poemas levados da breca); ou ainda de 0 gato e o escuro, de Mia Couto (pelo grupo Lua Cheia). Outros autores com peças publicadas vêem também outros textos seus, no domínio do não dramático, escolhidos para teatro: é o caso de Graças e desgraças de El-rei tadinho, de Alice Vieira; Ulisses, de Maria Alberta Menéres; ou O brincador, de Álvaro Magalhães.

Dos autores com obra dramática publicada, para além dos já anteriormente mencionados, nota-se ainda a presença no palco de peças de José Vaz, José Jorge Letria, Maria Alberta Menéres, Carlos Correia e, com menor expressão, Ilse Losa, António Gedeão (História breve da

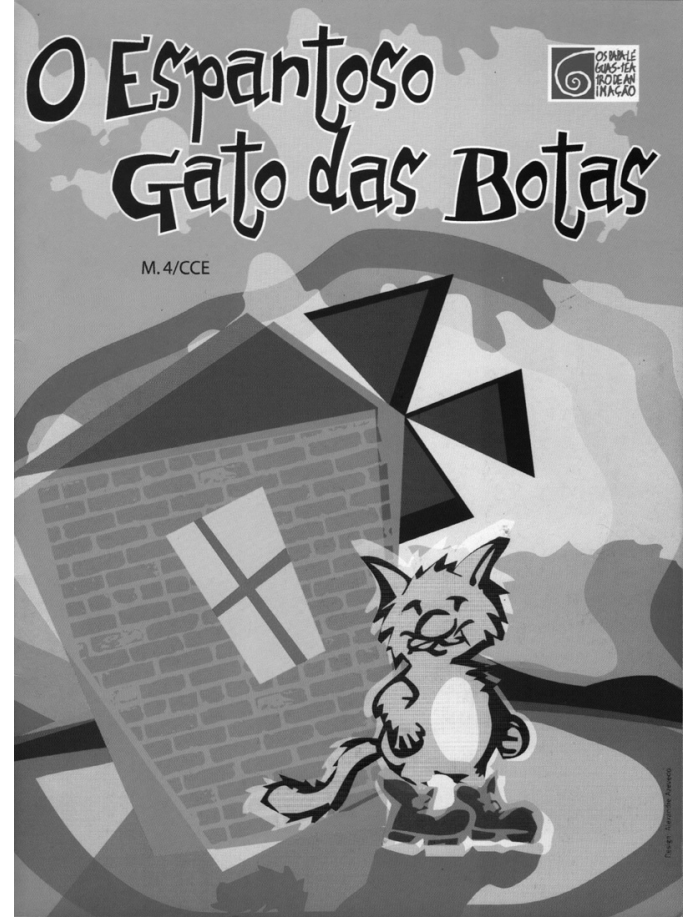

Programa do Festiva Sementes, org. Teatro Extremo, 2005

Programa do espectáculo Oespantoso gato das botas, texto e enc. Mário Jorge, Teatro de Animação Os Papa-Léguas, 2003.

lua), Manuel António Couto Viana, Alice Vieira (Leandro, rei da Helíria) ou António Ferra.

Pelo que ficou dito, constata-se que, de facto, a maioria dos grupos que desenvolve a sua actividade artística nesta área tem preferido, sobretudo, e por razões que não se pretendem agora indagar, a apresentação de adaptações de textos não dramáticos. 0 exemplo actual, porventura mais conhecido, será o do TIL - Teatro Infantil de Lisboa, que tem optado, nos últimos anos, por uma programação baseada em adaptações dramáticas, nomeadamente de conhecidas narrativas da literatura tradicional, a par com encenações em que a componente musical desempenha um lugar primordial na mise-en-scène.

Ora é sabido que a democratização cultural passa não só pelo alargamento dos públicos, mas também por um aumento do conjunto de criadores. $\mathrm{E}$ a partir do retrato delineado, podemos afirmar que, no que à publicação de textos dramáticos diz respeito, apenas um pequeníssimo segmento dos textos levados ao palco conhece essa oportunidade, com agravamento ainda no que se refere ao aparecimento de novos autores. Este aspecto não deixa de ter um certa projecção e impacto no contexto teatral, pois é exactamente a oportunidade que um dado texto conhece de ser passado a corpo de imprensa que the confere a possibilidade de adquirir uma projecção que transcende a do "aqui e agora" que caracteriza o espectáculo teatral. Ou seja, ter a possibilidade de ultrapassar as fronteiras do efémero e poder também alcançar uma maior divulgação, ao ser reapropriado por outras companhias e ao chegar, por essa via, a um número maior de espectadores. Analisando os elementos recolhidos, são os textos registados na forma escrita que encontramos retomados por novas companhias, com anos de intervalo e noutros pontos geográficos.

\section{Teatro e representação}

Olhando agora com mais atenção para o lado da representação, verificamos que ao longo das últimas três 
décadas foram surgindo numerosos grupos com formações e projectos diversos, em vários casos com um tempo de vida bastante curto. Das companhias que surgem nos tempos imediatamente a seguir à Revolução, um pequeno conjunto tem-se mantido até à actualidade, enquanto outras reorientaram o seu projecto, como 0 Bando (1974). No contexto da pós-revolução também outras companhias experimentam o terreno do teatro infantil: e se o trabalho do Teatro da Cornucópia - As músicas mágicas, de Catherine Dasté (1976), Zuca, Truca Bazaruca e Artur (1979) - não teve continuidade, em relação à Comuna teatro de pesquisa, a situação tem sido diferente. Depois do sucesso de Bão (1975, retomado em 1993 e em 2003 agora com a designação Bão preto), os espectáculos para os mais novos têm marcado presença na programação anual do grupo. Para além da parceria que, nos anos mais recentes, vai tendo com António Torrado, a Comuna apresentou ainda a peça publicada de Armando Nascimento Rosa, Lianor no país sem pilhas (2000), a par com várias adaptações para o palco (por exemplo, As aventura de João sem medo). Também o TAS - Teatro Animação de Setúbal (1975) continua a ser uma das companhias residentes que permanece fiel ao teatro para crianças, apresentando praticamente todos os anos uma peça infantil, mas recorrendo a textos não dramáticos (ao contrário do que acontece nas peças que inclui na programação para adultos).

De entre as companhias que surgiram ainda nos anos 70, e que se mantêm em actividade regular, refira-se, em particular, o TIL - Teatro Infantil de Lisboa (1976, Lisboa) o Teatro de Animação - Os Papa-léguas (1976, Lisboa), a companhia Pé de Vento (1978, Porto), Joana Grupo de Teatro (1978, Lisboa) e A Lanterna Mágica (1978, Lisboa: teatro de marionetas), estas duas com uma intervenção mais esporádica. Outras desapareceram entretanto, como - Centro Cultural de Évora - Unidade de Infância (19761989) ou 0 Realejo (1979-1989, Porto). Na década de 80 surgem no Porto duas das estruturas mais consistentes e com actividade mais permanente no panorama da representação para o público jovem: Art'Imagem (1981) e Teatro de Marionetas do Porto (1988), que têm desenvolvido um trabalho fundamental nas suas áreas de intervenção. 0 colectivo Teatro Art'Imagem é ainda responsável pelo festival de teatro infantil e juvenil com maior implantação e regularidade: em 2011 realizou-se a 30. edição do Fazer a Festa, Festival Internacional de Teatro para a Infância e Juventude (nos últimos anos tem aparecido apenas a designação Festival Internacional de Teatro, mas os objectivos continuam a privilegiar o público infanto-juvenil).

Mas é sobretudo na década de 90 que vemos aparecer um maior número de companhias a situar-se na esfera da representação para crianças. 0 aumento dos cursos na área do teatro, que vão lançando no mercado de trabalho jovens actores à procura de uma oportunidade para porem à prova as suas capacidades e o reconhecimento de que este é um campo em expansão, tem dado origem ao surgimento de pequenos grupos, alguns deles com a particularidade de escolherem nomes que remetem, de imediato, para o universo em que se pretendem movimentar - citem-se, como exemplos, Teatro do Imaginário, Oficina dos Desejos, Magia e Fantasia, 3 Em Pipa - Grupo de Teatro para a Infância, Vamos fazer de conta, Palmo e Meio, Pião, Boneca de Trapos, Crianças e Caminhos..

Em geral, são pequenos colectivos sem estruturas fixas, que procuram uma ligação ao contexto escolar, através do tipo de propostas que apresentam, situandose também em actividades afins e aproveitando as dinâmicas culturais que se vão criando: sensibilização e formação de crianças e jovens no âmbito da expressão dramática, contadores de histórias, participação em animação de rua e outros tipos de performance com carácter pontual. A possibilidade de apoios a projectos pessoais e ocasionais e a existência de iniciativas locais propiciam igualmente que estes grupos assumam novas configurações - e até novas designações - em função das oportunidades que vão surgindo. São grupos cujas produções são simples mas inventivas, com cenários facilmente transportáveis, uma vez que têm de apresentar os seus espectáculos em espaços muito distintos, de acordo com as solicitações, assumindo um importante papel na difusão do espectáculo teatral junto dos mais novos, por todo o pais.

A este propósito, será interessante assinalar que uma das iniciativas mais significativas que assumiu como propósito apoiar a descentralização das actividades culturais - o Programa Difusão das Artes do Espectáculo (PDAE), lançado pelo Instituto Português das Artes e do Espectáculo e que decorreu entre 1999 e 2002 - teve no teatro uma das suas facetas mais expressivas, ao constituir $44,8 \%$ do total de sessões realizadas (a oferta abrangia a música, dança e outras expressões). No relatório de avaliação efectuado pelo Observatório das Actividades Culturais (Santos 2004) regista-se uma atenção particular à formação de públicos, traduzida no incentivo a actividades como ateliês e ao envolvimento das escolas, com a expressão dramática a assumir também aqui a dianteira, pois 53,9\% das sessões situaram-se nessa área, com o espaço escolar e o da Biblioteca Pública a desenharemse como os locais privilegiados para esse tipo de acções, que em muitos casos foram asseguradas pelo género de colectivos a que nos referimos nos parágrafos anteriores.

Entre os grupos mais recentes e que têm conseguido manter uma actividade mais permanente, destacariamos: Pim-teatro (1994, Évora), Teatrão (1994, Coimbra), Teatro Bábá (1995, Amadora), Lua Cheia (1996, Lisboa), Teatro Extremo (1996, Almada), 0 Nariz - Teatro de Grupo (1997, Leiria), Quinta Parede - Associação de Artes Cénicas na Escola (1997, Porto; dinamizado por José Caldas, sobejamente conhecido pelo seu importante papel na divulgação do teatro junto do público jovem), Teatro do Elefante (1997, Setúbal), Trupilariante (1997, Lisboa), 


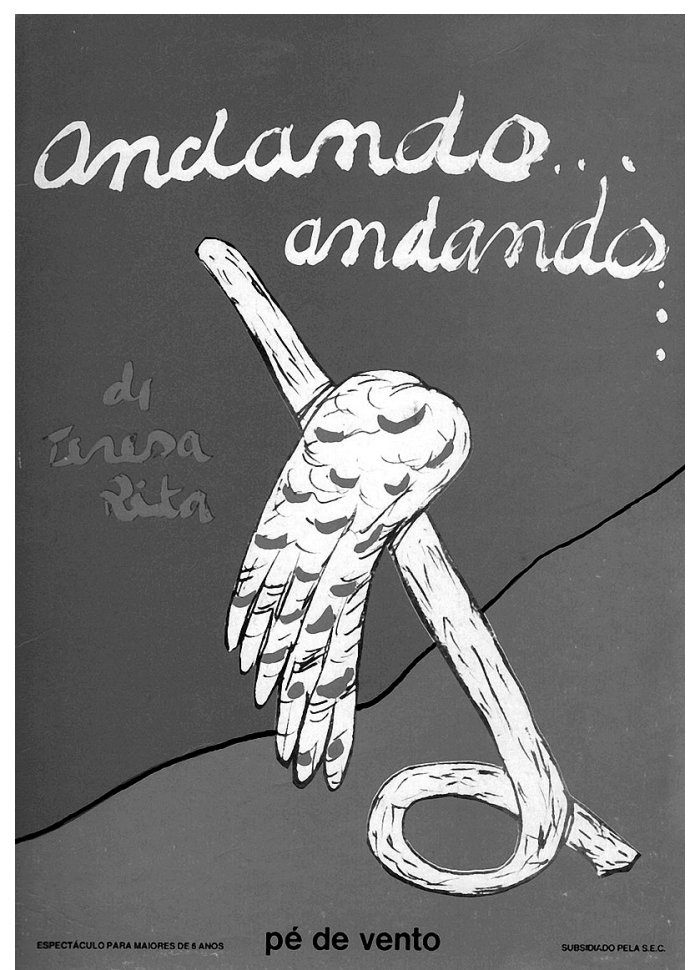

Companhia de Teatro de Marionetas - Os Valdevinos (1998, Cacém), Bica Teatro, Teatro Reflexo (2001, Sintra).

Mas outras companhias, na sua maioria com implantação regional - como o Arte Pública - Artes Performativas de Beja ou a Companhia de Teatro de Braga -, a que teremos ainda de acrescentar os grupos de teatro amador, vão incluindo no seu reportório peças de teatro para crianças, reconhecendo que estão igualmente a consolidar o seu público e tendo consciência de que, por enquanto, para eles, é de facto necessário um teatro especifico, como defende David Wood: "para captar o seu interesse e encorajar entusiasmo na leitura, as crianças precisam de livros que apelem directamente ao seu mundo, aos seus prazeres, aos seus medos e às suas experiências. De modo semelhante, o teatro para crianças pode abrir as portas a um novo mundo da imaginação, excitação e reflexão" (Wood 1997: 6).

Outros factores que dão visibilidade ao teatro para crianças são os festivais e neste capítulo pode afirmarse que em várias regiões do país se têm promovido eventos com essa natureza, embora nem sempre de forma consequente, na medida em que alguns acabam por não ter continuidade. Já mencionámos acima o Fazer a Festa (Porto), que surge como o festival mais representativo na área do teatro para o público jovem, tendo iniciado em 1982. Para além deste, registem-se ainda outros que têm tido várias edições: BITIJ - Bienal Internacional de Teatro para a Infância e Juventude (Beja, 7. a edição em 2009);

Kontunkonto - mostra de teatro para a infância e juventude

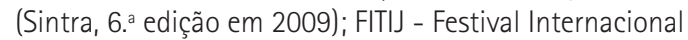
de Teatro para a Infância e Juventude (Santarém, 8. edição em 2008); Sementes - Mostra de Teatro para o Pequeno Público (Almada, 17. edição em 2012); Encontro Nacional de Teatro para a Infância e a Juventude (vários locais, 8. ${ }^{2}$ edição em 1990).

Juntem-se ainda os eventos no âmbito do teatro de Marionetas que, sem serem especificamente para crianças,

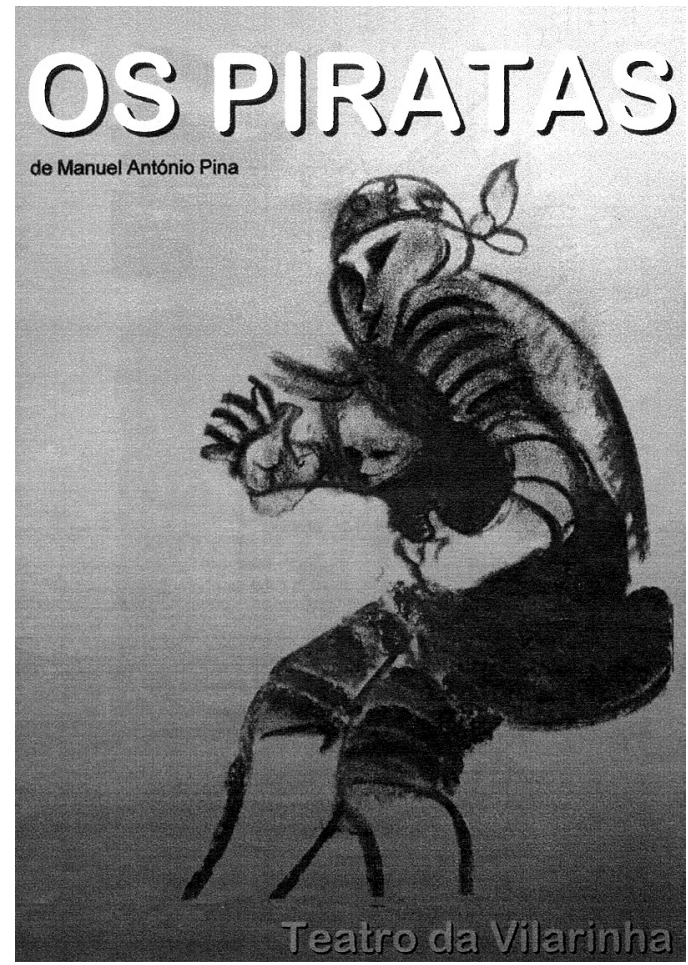

Programa do espectáculo Andando, andando... de Teresa Rita Lopes, enc. João Luiz, Pé de Vento, 1988

Programa do espectáculo Os piratas, de Manuel António Pina, enc. João Luiz, Pé de Vento, 1997

integram muitos espectáculos a elas especialmente destinados ${ }^{3}$ : BIME - Bienal Internacional de marionetas de Évora (11. a edição em 2011); FIMFA - Festival Internacional de Marionetas e Formas Animadas (Lisboa, 13. a edição em 2013), FESTAFIFE - Festival Internacional de Marionetas e Cinema de Animação (Viana do Castelo, 5. a edição em 2011) e o FIM - Festival Internacional de

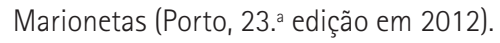

A nivel dos festivais, está ainda por realizar um estudo do impacto que estes vão tendo junto do público, quer em termos da participação do jovem público nestes eventos quer na formação de públicos. Na verdade, conferem uma dinâmica mais activa ao facto teatral, envolvendo-o, por um lado, na ludicidade da "festa", mas sendo, em simultâneo, importantes formas de desenvolvimento de uma "literacia cultural" (Conde 2004) ao potenciar o possivel envolvimento dos públicos (pela variedade oferecida, o que permite escolher, e pela concentração de espectáculos, o que pode levar a um maior consumo, pelo menos naquele momento) e ao conferir uma maior legitimação ao género teatral. São também espaços importantes para dar a conhecer propostas de outras latitudes, pois a sua dimensão frequentemente internacional possibilita o contacto com experiências diversificadas.

\section{Apontamentos finais}

Com o aparecimento de novas companhias com actores novos (também na idade) tem-se notado igualmente uma tentativa de aproximação a novos territórios expressivos. Uma dessas vertentes é o teatro para bebés, ou seja, propostas de expressão dramática/espectáculos dirigidos a crianças muito pequenas (com menos de 3 anos). Como exemplos, mencionem-se as peças apresentadas pelo Lua Cheia, À procura do ó-ó perdido (teatro de marionetas, para crianças de 1 a 5 anos) ou, da responsabilidade do Teatro do Elefante, Ipinêspêse Blim-Zim-Zim (para crianças
${ }^{3}$ Cf., para informações complementares, UNIMAP - União da Marioneta Portuguesa, Centro Português da UNIMA, http://www.unima portugal.com/ 
Programa do espectáculo

Cidade esmeralda

de António Cabrita

enc. Fernando Jorge

Lopes, Teatro Extremo,

2000.

Postal do espectáculo

A fada Oriana, de Sophia

de Mello Breyner,

enc. Rui Pisco,

Teatro Babá, 1998.

até 3 anos). Trata-se de propostas de expressão artística em que os aspectos sensoriais assumem grande importância, despertando os pequenos participantes para a fruição estética e dramatúrgica.

Outra novidade reside na introdução das novas tecnologias na representação: A aventura de Ulisses (2002 Teatro Nacional de D. Maria II) ou O inventão, a partir da peça de Manuel António Pina (1997, Teatro da Trindade) são exemplos de espectáculos que recorrem ao multimédia, numa eventual tentativa de incorporar no teatro meios que fazem parte da sociedade actual e, em especial, do quotidiano das crianças e jovens de hoje. Quando a produção o permite, assistimos à utilização de recursos expressivos e cénicos cada vez mais variados. Um apontamento também para a presença de peças infantis no âmbito das experiências de microteatro, pelo Teatro Rápido (Lisboa).

De qualquer forma, esta relativa multiplicação na oferta de teatro para o público mais novo assume um destaque particular em certo momento do ano, isto é, no período natalício. É nessa altura que se verifica uma acentuada concentração na oferta de espectáculos para crianças, designadamente de teatro. Esta cultura das "Boas Festas", na expressão de José Machado Pais (2004), que concentra num determinado período do ano a oferta cultural não deixa de ser sintomática de uma certa visão do consumo cultural, por parte dos públicos e alimentada pelos criadores. De facto, neste sentido, ir ao teatro com as crianças não é entendido como um elemento que faz parte dos hábitos mas como um "acontecimento", ou seja uma ocorrência pontual, neste caso uma espécie de "prenda de Natal", pelo que o papel da mediação na recepção do teatro assume um papel determinante, que importaria aprofundar. E esta situação concorre, na verdade, para dificultar os processos de fidelização e de alargamento de novos públicos (Lopes 2004), consumidores de teatro escrito e de teatro visto.

\section{Referências bibliográficas}

BASTOS, Glória (2006), O teatro para crianças em Portugal: História e critica Lisboa, Editorial Caminho.

LOPES, João Teixeira (2004), "Experiência estética e formação de públicos", in Públicos da cultura, Actas do Encontro organizados pelo OAC. Lisboa, OAC, pp. 43-54.

PAIS, José Machado (2004), "A cultura das "Boas festas" - seus vinculos, seus públicos", in Públicos da Cultura, Actas do Encontro organizado pelo OAC. Lisboa, OAC, pp. 55-75.

SANTOS, Maria de Lourdes Lima (coord.) (2004), Politicas culturais e descentralização: Impactos do programa difusão das artes do espectáculo, Lisboa, OAC

SERÔDIO, Maria Helena (1998), "Theatre as a social system", in H. Van Maanen / S. E. Wilmer (Ed.). Theatre worlds in motion: structures, politics and developments in the countries of Western Europe, Amsterdam \&t Atlanta, Rodopi, pp. 498-539.

WOOD, David (1997), Theatre for Children, London, Faber and Faber.
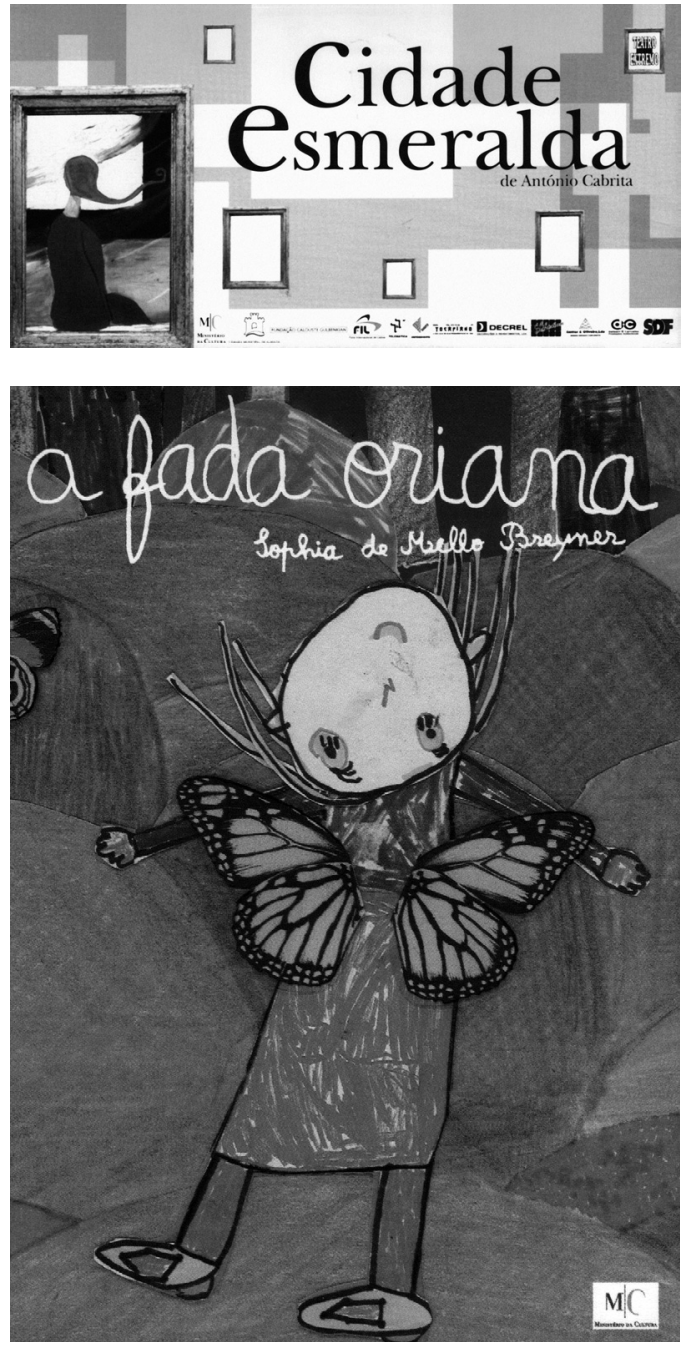

Anexo - Peças (ou volumes de peças) publicadas entre 1980 e 2010 (assinalam-se as reedições)

ALÇADA, Isabel / MAGALHÃES, Ana Maria (2004), "As Rainhas Magas", in Natal, Natal, Lisboa, Caminho.

ALDINA, Maria (1994), Jesus nasceu: Peça de teatro, Lisboa, Patriarcado,

Secretaria do Diocesano da Catequese.

ALMEIDA, Etelvina Lopes de (1985), Histórias que o mundo conta, Lisboa, Perspectivas e Realidades.

ALMEIDA, Ribeiro de (1994), Teatro na escola, Viseu, Edição autor. ANDRÉ, Fernando dos Santos (1981), O porco e o burro, S.I.[Setúbal], S.n. -- (1981), A cegonha e a raposa, S.I. [Setúbal], S.n.

ANDRESEN, Sophia de Mello Breyner (2000), O Bojador, Lisboa, Caminho. ÁVILA, Norberto (1982), Histórias de Hakim, Lisboa, APTA (reed.)

-- (1990), Magalona princesa de Nápoles, Angra do Heroismo, D-R dos

Assuntos Sociais/Secretaria Regional da Educação e Cultura.

BARROS, Orlando Ferreira de (1981), Ariô-Ariela, Odivelas, Edições 1 de Outubro.

BENTO, Avelino (1987), Histórias de brinquedos com história, Portalegre, ESSE.

CABRAL, António Pires (1980), Crispim, o grilo mágico, Lisboa, Ulmeiro. CABRAL, Maria Alzira (1988), O sonho do palhaço, Lisboa, Plátano. CARDOSO, João Paulo Seara (2001), Polegarzinho, Porto, Campo das Letras. -- (2003), História da Praia Grande, Porto, Campo das Letras.

-- (2003), Óscar, Porto, Campo das Letras.

-- (2005), A cor do céu, Porto, Campo das Letras.

-- (2008), Como um carrossel à volta do Sol, Porto, Campo das Letras. 
-- (2008), Bichos do bosque, Porto, Campo das Letras.

-- (2010), Cinderela, Porto, Porto Editora.

CARVALHO, Mendes de / NEVES, Orlando / FEIO, António (1982), Aventuras de animais e outros que tais, Lisboa, Plátano.

CÓIAS, Elisa (1989), o filho pródigo (que o pai não aceitava) e Outras Peças, Queluz, Núcleo.

COLAÇO, Maria Rosa (1981), O espanta-pardais, Lisboa, Plátano.

CORREIA, Carlos (1982), O chapéu mágico, Lisboa, Sá da Costa.

-- (1988a), Carnaval infernal, Lisboa, Plátano.

-- (1988b), O sabor dos sonhos, Lisboa, Rolim.

-- (1988c), Os cozinheiros de Oz, Lisboa, Plátano.

-- (1988d), A revolta dos micróbios, Lisboa, Plátano.

CORREIA, Hélia (2003), Sonho de uma noite de verão (W. Shakespeare; versão infantil de H. C.), Lisboa, Relógio D'Água.

_- (2008), A ilha encantada, Lisboa, Relógio D'Água.

COSTA, Manuel Pereira da (1992), Um gira-discos na floresta, Lisboa, Inatel. COSTA, Soledade Martinho (1985), 0 canteiro vaidoso, Porto, Figueirinhas. DACOSTA, Luisa (1995), Robertices, Porto, Civilização.

FALCÃO, Bernardette (1983), Andorinha e as árvores falantes, Funchal, C.M. Funchal.

FERRA, António (1981), Caleidoscópio, Lisboa, Moraes.

-- (1995), Histórias e teatrada com alguma bicharada, Lisboa, Europress. FERREIRA, José Pedrosa (1987), Viva o teatro: Peças breves, Porto, Ed. Salesianas.

-- (1990a), O sal e a luz: Dramatizações para a catequese, Porto, Ed. Salesianas.

-_ (1990b), Festa na escola, Porto, Ed. Salesianas (2.a ed., 1996).

-- (1993a), Todos em acção: Dramatizações para todo o ano, Porto, Ed. Salesianas.

-- (1993b), Teatrinho, Porto, Ed. Salesianas.

-- (1998), O sal da paz: Dramatizações do Evangelho, Porto, Ed. Salesianas.

FIGUEIRA, Jorge Louraço (2004), Xmas qd Kiseres (Christmas quando uiseres), Porto, Campo das Letras.

GEDEÃO, António (1981), História breve da lua, Lisboa, Sá da Costa. GPDINHO, Sérgio (1980), Eu, tu, ele, nós, vós, eles, Lisboa, Moraes.

GOMES, Luisa Costa (1993), Ubardo, seguido de A minha Austrália, Lisboa, D. Quixote (embora sem a indicação de ser para crianças, a peça

"Ubardo" remete para um ambiente infantil).

-- (1999), Vanessa vai à luta, Lisboa, Cotovia.

GONZALEZ, Maria Teresa Maia (2003), Os herdeiros da Lua de Joana, Lisboa, Verbo.

-- (2004), A rapariga voadora, Lisboa, Verbo.

-- (2005), Os Campistas, Lisboa, Verbo.

-- (2006a), Clube de actores, Lisboa, Verbo.

-- (2006b), O amigo do computador, Lisboa, Verbo.

GUIMARÃES, Adriana da Cruz (1987), Histórias para representar, Porto Figueirinhas.

LEITÃo, Olivia (1983), Para festas infantis no palco, Viseu, Edição autor.

LETRIA, José Jorge (1984), Papão e o sonho, Lisboa, SPA.

-- (1993), O pequeno teatro, Lisboa, Edições Paulistas.

LOBO, Fernando (1987), Ícaro, o balão azul, Lisboa, Livros Horizonte.

LOPES, A. M. da Cunha (1986), A derrota do Kid Labaredas, Lisboa, ACEL - Assoc. das Emp. Produtoras de Pasta de Celulose.

LOPES, Teresa Rita (1992), "Romance da mal-maridada", in Teatro I, Lisboa, De viva voz.

-- (1999), Andando, andando, Porto, Campo das Letras.
-- (2004), A asa e a casa, Porto, Campo das Letras.

LOSA, Ilse (1984), João e Guida, Porto, Asa (reed.)

-- (1994), A adivinha, Porto, Afrontamento (reed.)

MACEDO, Agostinho (1980), Aventura dos palhaços amigos, Lisboa, Fungága. MACHADO, Maria Alzira Pires (1982), Natalinho, Porto, MAM

Magalhães, Álvaro (2000), Enquanto a cidade dorme, Porto, Campo das Letras.

-- (2004), Todos os rapazes são gatos, Porto, Asa.

MARQUES, Raul Malaquias (1992), Um bobo para o reino, Lisboa, Caminho. MARTINS, Jorge (2003), História alegre de Odivelas, Odivelas, CESDIS MATOS, Ana Isabel / ROQUE, Cesaltina / MENDES, Isabel / RAMOS, M. Cristina / CASTANHEIRA, Paula (1988), Pequenas peças de teatro para crianças, Setúbal, I. Matos.

MENÉRES, Maria Alberta (1980), 0 que é que aconteceu na terra dos Procópios?, Lisboa, Moraes.

-- (1984), 0 tritão centenário, Lisboa, D. Quixote.

-- (1991), "Noite de Natal", in O livro do Natal, Porto, Desabrochar.

-- (1995), Á beira do Lago dos Encantos, Porto, Asa.

MIRANDA, Maria Natália (1983), Hoje há robertos, Porto, Asa

MOURÃO, Luis (1999), O homem que via passar as estrelas, Lisboa, Teatro da Trindade/Inatel.

-- (2005), O verdadeiro livro dos sonhos e outros textos de teatro para a infância, S.I., "O Nariz", Grupo de Teatro.

MOUTINHO, José Viale (2005), Histórias da deserta grande, Porto, Afrontamento.

MÜLLER, Adolfo Simões (1983), A re(vira)volta dos fantoches, Lisboa, Distri. NAMORADO, Maria Lúcia (1984), 0 segredo da Serra Azul, Lisboa, Livros Horizonte.

NERY, Júlia (1993), Na Casa da Lingua moram as Palavras, Porto, Asa.

-- (1994), O Plantador de Naus a Haver, Porto, Asa.

NEVES, Orlando (1991), O tio Maravilhas, Lisboa, Património XX.

-- (1992), O mosquito ZZZ, Lisboa, Inatel.

-- (1999), Teatro para crianças, Lisboa, Matéria Escrita.

NOGUEIRA, Manuela (1998), Teatro na escola, Lisboa, Nova Arrancada.

OLIVEIRA, Carlos de (1991), Abidis, a lenda de Santarém, Santarém, Inatel.

PEDRO, Lúcia Vaz (2008), A viagem das três gotinhas de água, V. N. Gaia, Gailivro.

PEREIRA, Isabel (1985), Más caras e máscaras, Faro, Teatro Laboratório de Faro.

PINA, Manuel António (1983), Os dois ladrões, Porto, Afrontamento.

-- (1983), História com reis, rainhas, bobos, bombeiros e galinhas, Porto, Pé de Vento.

-- (1987), O Inventão, Porto, Afrontamento.

-- (1997), Os Piratas, Porto, Afrontamento.

-- (1998), Aquilo que os olhos vêem ou O Adamastor, Porto, Campo das Letras.

-- (2001), A noite, Porto, Campo das Letras.

-- (2004), História com reis, rainhas, bobos, bombeiros e galinhase $A$ guerra do tabuleiro de xadrez, Porto, Campo das Letras.

PIGNATELLI, Inácio Nuno (1999), Um roubo na véspera do Natal, Porto, Campo das Letras.

-- (2001), A verdadeira história da batalha de S. Mamede, Porto, Campo das Letras.

PIRES, José (2008), A viagem, S.I., Gráfica do Tortosendo.

PYRRO, Mário (1989), Uma escola especial, Porto, Salesianas.

-- (1989), Os olhos do planeta, Porto, Salesianas. 


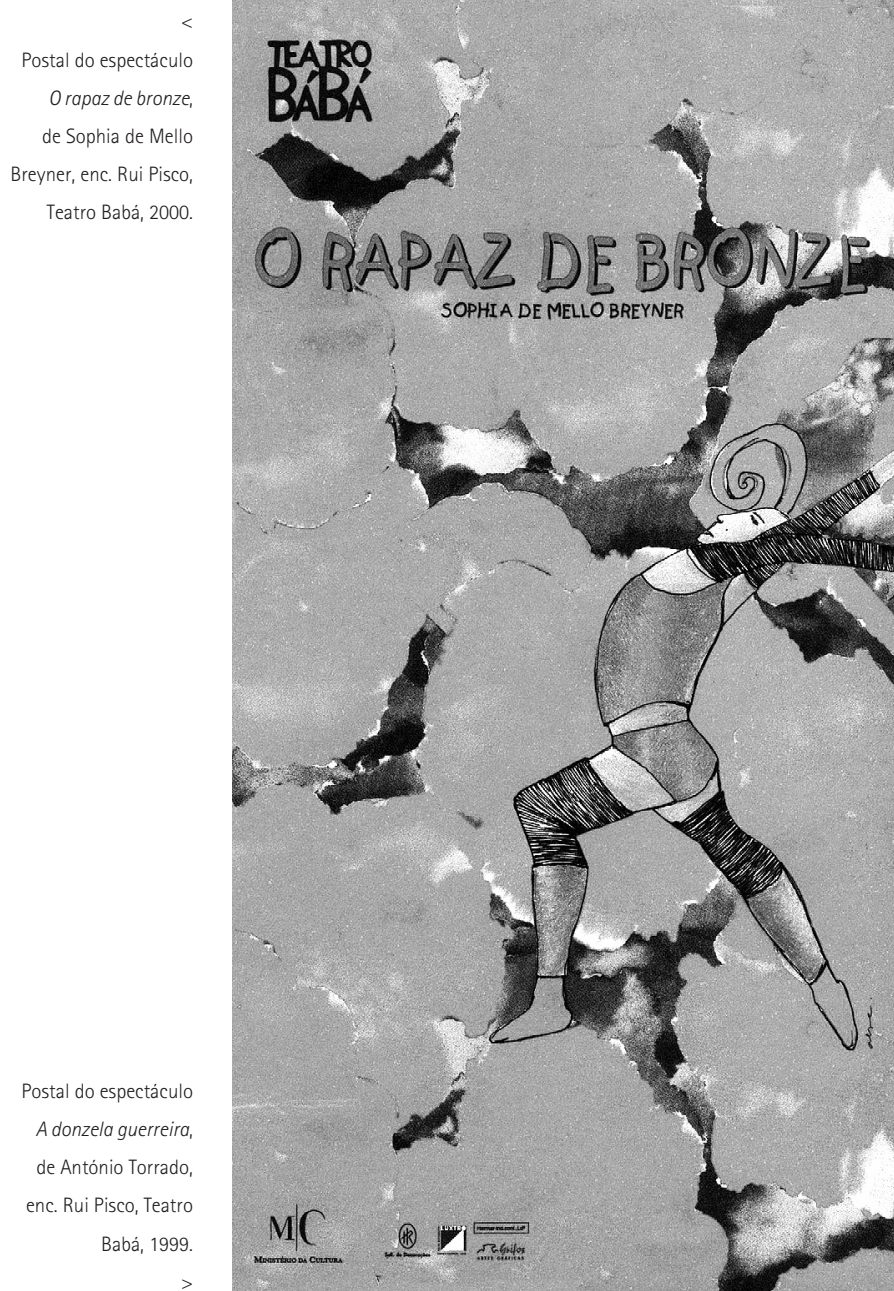

QUINTAS, Fausto Alberto Pereira (1980), Os Meninos e os Palhaços, Lisboa Moraes.

-- (1991), O sonho do mágico, S.I., Edição autor.

REBELO, Luisa (1997), O dragão comilão, outras histórias e peças infantis,

Lisboa, Acontecimento.

RÉGIO, José (1989), Sonho de uma Véspera de Exame, Vila do Conde, Casa José Régio/C.M. Vila do Conde.

ROCHA, Natércia (2003), Teatro do Gato do Chapéu Alto, Lisboa, Caminho. RODRIGUES, Carlos M./ ANÇÃ, M. Helena / CABRAL, A. M. (1980), 0 cavalo mágico, Lisboa, Ulmeiro.

ROSA, Armando Nascimento (2001), Lianor no pais sem pilhas, Porto,

Campo das Letras.

SAMPAIO, Jaime Salazar (1981), Árvores, verdes árvores, Lisboa, Plátano. SANTOS, Margarida Fonseca (2001), A cegonha quer... mas não manda!

Schering Lusitana.

-- (2007a), Um quadro falador, Lisboa, Sete Caminhos.

-- (2007b), Ao encontro do Brasil, Lisboa, Sete Caminhos.

-- (2008), O nosso clube de teatro, Lisboa, Presença.

SILVA, Gualberto Gonçalves (1980), o Circo Fantasia ou o Palhaço Teimoso, Lisboa, Moraes.

SILVA, Margarida (1992), Teatro para crianças, S.I., s.n

SILVA, Ramos da (1985), Trocas e Baldrocas, S.I., s.n.

SIMÕES, Joaquim António dos Santos (1997), D. Tão Parlatão, Guimarães, Gráf. Covense.

SOARES, Luisa Ducla (2002), As viagens de Gulliver, Porto, Civilização SOUZA, José Dias de (1981), 0 encantado do nevoeiro, Lisboa, Moraes

Editores.

TORRADO, António (1984), O adorável homem das neves, Lisboa, Caminho.
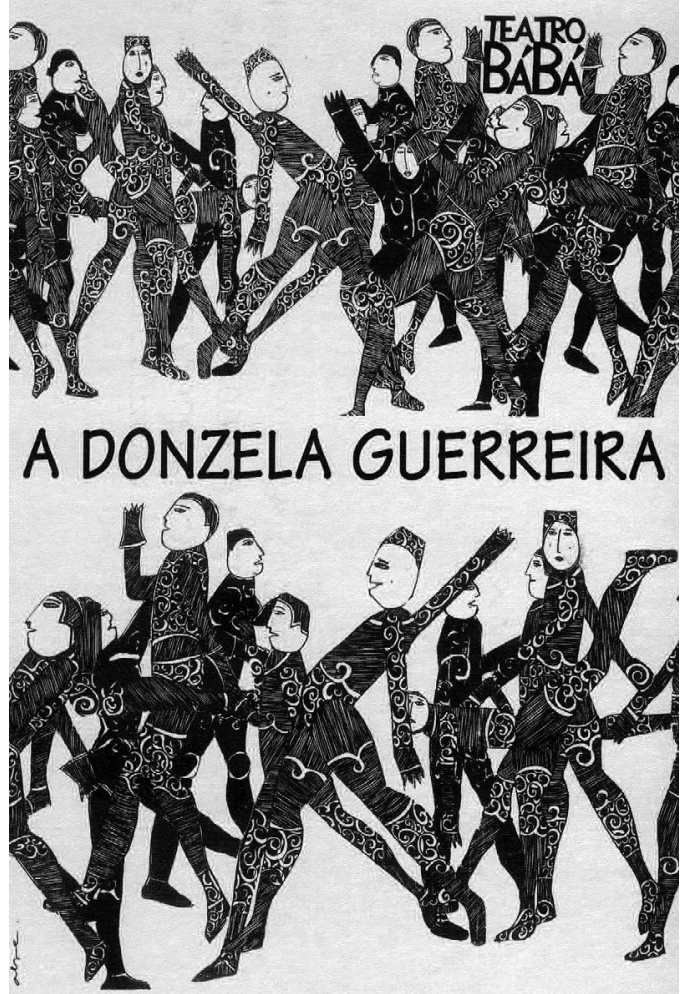

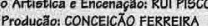
Cenografia/Figurinos ALBERTO REIS o HELENA MACEDO
Iluminagăa: PEDRO DOMINGOS

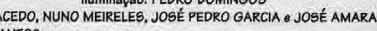
Apoio (Yoz): FERNANDO SANTOS
Apolo (CorPo): PAULA CARETO

SOCIEDADE de INSTRUÇÃO GUILHERME COSSOUL - AV. D. CARLOS 1, 61-1.0 - TEL. 3973471 Sábados: 16.30 Domingos: 11.30

-- (1987), Zaca Zaca, Lisboa, Rolim.

-- (1992), Toca e foge ou a flauta sem mágica, Lisboa, Caminho.

-- (1995), Teatro às Três Pancadas, Porto, Civilização.

-- (1996), A donzela guerreira Porto, Civilização.

-- (1999), Os doze de Inglaterra, Lisboa, Caminho.

-- (2002), Verdes são os campos, Porto, Campo das Letras.

-- (2005), O homem sem sombra, Lisboa, Caminho.

-- (2007), Era uma vez quatro, Lisboa, Caminho.

-- (2008a), O mistério da cidade de Hic-Hec-Hoc, Coimbra, Calendário/ Teatrão.

-- (2008b), Xerazade não está só, S. I., Artemrede.

VALE, Fernando (2000), Teatro, histórias e rimas para crianças, Lisboa, Instituto Piaget.

-- (2001), Histórias de ontem e teatro de hoje, Lisboa, Instituto Piaget.

VAZ, José (1983), O Rei Lambão, Lisboa, Base (2. ed., Gailivro, 1999).

-- (1988), A ilha mágica, Porto, Asa.

-- (2001), Na feira dos malandrecos, Gaia, Gailivro.

-- (2002), 0 mandarim Xi-Fú. Gaia, Gailivro.

VIANA, Manuel António Couto (1997), Teatro infantil e juvenil, Lisboa, Nova Arrancada (reúne todas as peças do autor).

VIANA, Maria Adelaide Couto (1996), "Também os bonecos falam", "0 terreiro e a montanha", in Caminhos que dão para a vida, Viana do Castelo, Câmara Municipal de V. do Castelo.

VEIRA, Alice (1991), Leandro, rei da Helíria, Lisboa, Caminho.

VIEIRA, Vergilio Alberto (1998), O saco de mentiras, Lisboa, Caminho.

-- (2001), 0 circo de papel, Lisboa, Caminho.

_- (2007), O menino Jesus da cartolinha, Porto, Campo das Letras. 